\title{
Kinematic Elicitation of Basic Emotions: A Validation Study in an Italian Sample
}

\author{
Cesare Maffei1,2, Emanuela Roder1,2, Claudia Cortesan'2, Francesca Passera1, \\ Massimo Rossi2, Martina Segrini2, Raffaele Visintini'2, Andrea Fossati2,3 \\ ${ }^{1}$ Faculty of Psychology, Vita-Salute San Raffaele University, Milan, Italy \\ ${ }^{2}$ Department of Clinical Neurosciences, San Raffaele Hospital, Milan, Italy \\ ${ }^{3}$ Department of Human Studies, LUMSA University, Rome, Italy \\ Email: maffei.cesare@hsr.it
}

Received 13 May 2014; revised 12 June 2014; accepted 8 July 2014

Copyright (C) 2014 by authors and Scientific Research Publishing Inc.

This work is licensed under the Creative Commons Attribution International License (CC BY). http://creativecommons.org/licenses/by/4.0/

(c) (i) Open Access

\section{Abstract}

Video clips proved to effectively elicit different emotions. Hewig and colleagues (2005) developed a comprehensive set collecting 20 emotional film clips and investigated the basic emotions elicited in a German sample. In this study, we tested the reproducibility of their findings in Italian nonclinical adult subjects $(N=32)$ examined individually in an ecological setting; moreover, the differences between presentation modalities (with and without sound) were examined. Clips were rated on 10 emotional states (serene, amused, happy, surprised, sad, scared, angry, disgusted, indignant, tense) and on two bipolar dimensions of valence and intensity. Only little differences between presentation modalities were found; stories depicted proved to be clear enough. Film clips elicited the expected emotional profiles, and their rank order for each emotion is almost comparable with the German ones. However, all the clips elicited more than one emotion: ANCOVA proved that emotions were not fully independent and specific association patterns were found. Implications are discussed in the light of the complexity of emotional activation.

\section{Keywords}

Emotion, Measurement, Films, Emotion Elicitation, Cross-Cultural Studies

\section{Introduction}

Emotion elicitation and assessment is one of the most intriguing, although complex and vexing, questions in emotion research field (Darwin, 1872; Davidson, Goldsmith, \& Scherer, 2003; Coan \& Allen, 2007; Gross, 2010). One important question is about using static versus dynamic stimuli. Lots of researches consider static 
material, such as emotional pictures (Lang, Greenwald, Bradley, \& Hamm, 1993; Bradley \& Lang, 2007; Bradley, Hamby, Low, \& Lang, 2007), or faces designed to elicit and code emotions (Russell, 1995; Haidt \& Keltner, 1999; Ekman, Friesen, \& Hager, 2002; Kring \& Sloan, 2007). Anyway, since emotions unfold over time (Mesquita, 2003), this can be more effectively captured by film viewing (Mauss, Levenson, McCarter, Wilhelm, \& Gross, 2005): the relative potency of films as emotional stimuli may be due in part to the fact that clips tend to be dynamic, multimodal, and reliant on a narrative (Rottenberg, Ray, \& Gross, 2007; Lazar \& Pearlman-Avnion, 2014). The use of dynamical stimuli, such as selected film clips to elicit specific emotions, developed and became more accurate along with the recent progression of affective sciences (Gerrards-Hesse, Spies, \& Hesse, 1994; Hagemann et al., 1999). Until now, research groups who have used emotional films for years have demonstrated this procedure has distinctive features (Gross \& Levenson, 1995; Philippot, 1993; Hewig et al., 2005; Lazar \& Pearlman-Avnion, 2014).

First, films have high ecological validity for their closeness to real life situations (Mauss \& Robinson, 2009), although the involvement is tempered by the fact that experimental subjects are audience and they can just recreate a fictional representation of reality (Frijda, 1989). Second, video stimuli calls for a considerable appraisal both in perceptual (multimodality, temporal dynamism) and cognitive (attentive resources, comprehension of meaningful content) terms: films' complexity can vary to a great extent, since the demand depends partly on the degree to which history, characters' feelings, and target emotions are ambiguous or multifaceted (Rottenberg et al., 2007). Third, films show good standardization properties: stimuli features, instructions and setting can be defined a priori, controlled, and thus replicated across samples (Gross \& Levenson, 1995).

Emotion assessment shows different levels of difficulty (Rottenberg et al., 2007). Amusement, disgust and sadness can be elicited by several film clips (Gross \& Levenson, 1995; Gross, Sutton, \& Ketelaar, 1998). Anger and fear are, instead, quite difficult to elicit: the former requires high level of personal engagement or identification with characters (Gross \& Levenson, 1995; Philippot, 1993); the latter tends to be associated with other similar feelings and it shows higher scores for women than for men (Rottenberg, Kasch, Gross, \& Gotlib, 2002). Surprise has rapid onset and offset, and it is usually followed by more clearly valence-connoted emotions (Rottenberg et al., 2007). Neutral clips are a very heterogeneous category: some provoke very little activation, such as abstract displays (Gross \& Levenson, 1995), while low levels of contentment are elicited by those that depict a relaxing situation (e.g., a nature scenery; Rottenberg et al., 2002) or a serene social interaction (e.g., a quiet interpersonal scene; Hewig et al., 2005).

In a recent study, Hewig et al. (2005) proposed a new set of films for the elicitation of basic emotional states. They included sixteen emotional film clips from previous studies (Boiten, 1998; Gross \& Levenson, 1995; Philippot, 1993; Tomarken, Davidson, \& Henriques, 1990) which successfully elicited fear, anger, sadness, disgust and amusement. In order to overcome the difficulties deriving from the lack of comparable neutral stimuli, they completed the film set with four clips which were supposed to be emotionally neutral. The inventory for the assessment of the emotional reaction comprised 21 emotion-related items: happiness, pleasure, amusement, hope, affection, desire, sympathy/empathy, relief, boredom, frustration, anger, rage, sadness, fear, disgust, shame and guilt. In addition, they included four bipolar ratings according to the theoretical background of Russell's (2003) circumplex model of emotion (unpleasant vs. pleasant, weak vs. strong, stressed vs. content, ecstatic vs. depressed). Cluster analysis of all monopolar emotional ratings showed the presence of five groups for the five different target emotions: anger, disgust, fear, happiness/amusement, sadness and of a separate sixth group of neutral clips. A subsequent analysis focused on the capacity of each film clip to elicit the specific target emotion without eliciting one of the other four target emotions. All film clips, except three of them, met the criterion of eliciting their respective target emotion to a significantly higher degree than any other target emotion. The neutral clips showed somewhat increased positive as compared to negative affective ratings. However, these differences were on a rather low level of the rated emotions. As the film set was initially developed for brain asymmetry research, the films were shown silent. This was necessary in order to avoid confounding influences of speech, music, and sounds on asymmetry measures (Tomarken et al., 1990).

\section{Aims}

Our aim was to replicate the results of Hewig and colleagues (2005) in an Italian sample-as Sato and colleagues (2007) did for Gross and Levenson (1995) film set. Two more aspects were taken into consideration. First, the difference between two kinds of presentation, with and without sound: we considered that for general re- 
search purpose, it is necessary to know if the presence of sound modifies the emotional reactivity. Second, since literature offers evidences that the presence of other people (i.e., friends, strangers) could enhance the perception and the expression of some emotions, while other ones could be inhibited (Fridlund, 1991; Jakobs, 2001; Bruder, Dosmukhambetova, Nerb, \& Manstead, 2012), we presented the clips in an individual setting in order to avoid effects due to collective presentation.

We considered three levels of analysis:

- Broad dimensions, common to all clips, of overall mood pleasantness and intensity, plots' clarity and characters' comprehension, examining the scores of each clip and the relations between these variables;

- Emotional profile of clips, computing comparisons between (that is, identifying the highest ones) and within stimuli (that is, primary and secondary emotions);

- The relations between emotions elicited by the film set, in order to examine if they could be considered independent or not.

In summary, we wanted identify emotionally specific clips and compare our results to Hewig's et al. (2005) ones.

\section{Method}

\subsection{Video Clips}

The stimulus set consisted of the Italian version of the 20 video clips extracted from commercial films and used by Hewig and colleagues (2005); many of them were taken from previous film set (Tomarken et al., 1990; Philippot, 1993; Gross \& Levenson, 1995; Boiten, 1998). Clips were designed to elicit target emotions of amusement, sadness, fear, disgust, anger, and there were four emotionally neutral ones. Since we presented clips with sound, we had to cut Hannah (from 92 seconds to 91 seconds) and Crimes (from 63 seconds to 57 seconds) to prevent confound effects due to dialogues contents. Clips' durations ranged from 29" to 3'56"; the mean length was 1' and 53" ( $S D=60.3 ")$. Table 1 provides short descriptions of the film clips.

\subsection{Sample}

The sample was composed of 32 non-clinical young adult subjects, with a negative medical history for psychiatric or neurological disorders, nor for psychological problems. All participants were native Italian speakers and had normal or corrected-to-normal vision. The subjects were volunteers recruited by experimenters; all of them were university students. The sample was composed by 16 males and 16 females, between the ages of 20 and 27 years $(M=23.34, S D=2.31)$. Age distribution was not influenced by gender, Mann-Whitney $U=117, n_{1}=n_{2}=$ $16, p>$.6. The study has been approved by Ethic Committee of Research of Vita-Salute San Raffaele University. All participants gave their written informed consent to the study protocol.

\subsection{Procedure}

The whole procedure was carried out individually in an ecological setting. Participants were randomly assigned to two experimental conditions, clips' presentation with or without sound; groups were balanced on sex. In order to avoid any carry-over effect due to possible sequences of similar emotions, clips were administered in a pseudo-random order using counter balanced sequences in respect to clips' valence (positive, negative, and neutral).

Before starting, we induced relax and calm; as Hewig (Hewig et al., 2005) did, we started always with Hannah to make participants confidential and to give a constant baseline stimulus (Hagemann et al., 1999). Clips were shown on a 15.6 inch pc and the person was seated at a distance of approximately $40 \mathrm{~cm}$ from the screen. We asked participants to watch carefully every video clip and immediately fill in a short questionnaire, which was composed of five sections:

1) The specific emotions elicited during the showing: 10 emotional states (serene, amused, happy, surprised, sad, scared, angry, disgusted, indignant, tense) were measured on a Likert scale ranging from 0 ("not at all”) to 7 ("very much"); these emotions were selected from the so-called basic ones (i.e., Ekman, 1972), but for some of them we preferred to assess in addition lower gradations in order to verify if they could represent qualitatively distinguishable variants for our stimuli.

2) The valence of the global mood generated by each videoclip and its intensity, according to Russell's model 
Table 1. Clips’ description and notoriety statistics in our sample $(N=32)$.

\begin{tabular}{|c|c|c|c|c|}
\hline Emotion & Clip & Film & Length & Clips' Notoriety \\
\hline \multirow[t]{3}{*}{ Amusement } & Golden & On Golden Pond (Universal Pictures, 1981) & $32 "$ & 0 \\
\hline & Officer 1 & An Officer and a Gentleman (Lorimar Film Entertainment, 1982) & 1'51" & $15(46.9 \%)$ \\
\hline & Harry & When Harry met Sally (New Line Cinema, 1989) & 2'29" & $21(65.6 \%)$ \\
\hline \multirow[t]{4}{*}{ Anger } & Gandhi & Gandhi (Goldcrest Films International, 1982) & 2'08" & $5(15.6 \%)$ \\
\hline & Witness & Witness (Paramount Pictures, 1985) & 1'31" & $2(6.3 \%)$ \\
\hline & Cry & Cry Freedom (Marble Arch/Universal, 1987) & 2'30" & $2(6.3 \%)$ \\
\hline & Bodyguard & My Bodyguard (20th Century Fox, 1980) & 3'56" & $1(3.1 \%)$ \\
\hline \multirow[t]{3}{*}{ Disgust } & Godfather & The Godfather (Paramount Pictures, 1972) & $59 "$ & $12(37.5 \%)$ \\
\hline & Maria & Maria’s Lovers (Cannon Films, 1984) & $58 "$ & 0 \\
\hline & Pink & Pink Flamingos (Dreamland, 1972) & $29 "$ & $1(3.1 \%)$ \\
\hline \multirow[t]{3}{*}{ Fear } & Silence & Silence of the Lambs (Orion Pictures, 1991) & 3'22" & $24(75 \%)$ \\
\hline & Halloween & Halloween (Falcon Films, 1978) & 3'28" & $3(9.4 \%)$ \\
\hline & Marathon & Marathon Man (Paramount Pictures, 1976) & 2'41" & $5(15.6 \%)$ \\
\hline \multirow[t]{3}{*}{ Sadness } & Officer 2 & An Officer and a Gentleman (Lorimar Film Entertainment, 1982) & 1'41" & $13(40.6 \%)$ \\
\hline & Killing & The Killing Fields (Goldcrest Films Ltd., 1984) & 1'23" & $1(3.1 \%)$ \\
\hline & Champ & The Champ (Metro-Goldwyn-Mayer MGM, 1979) & 2'51" & $3(9.4 \%)$ \\
\hline Neutral & Hannah & Hannah and her Sisters (Orion Pictures, 1986) & 1'31" & 0 \\
\hline \multirow[t]{3}{*}{ Clips } & Emperor & The Last Emperor (Hemdale Film Corporation/Columbia Pictures, 1989) & 1'15" & $2(6.3 \%)$ \\
\hline & Crimes & Crimes and Misdemeanors (Orion Pictures, 1989) & $57 "$ & 0 \\
\hline & President & All the President's Men (Warner Bros/Wildwood, 1976) & 1'05" & $2(6.3 \%)$ \\
\hline
\end{tabular}

of emotions (2003), both measured on a bipolar dimension and assessed with a Likert scale ranging from 0 to 7 ;

3) Evaluation of clarity of the story depicted and ease of understanding the moods of characters, assessed on a 5 point Likert scale (from 0 "not at all”, to 4 "absolutely true");

4) Assessment of prior knowledge of the clip.

We further examined the presence of disturbing elements: these data are available in supplementary material.

The questionnaire could be completed by the subject without limitation of time: it takes usually few minutes, and we thought that this could be enough to emotionally space out the clips (Wilson \& Schooler, 1991). After every session we checked if the clip had caused psychological reactions interfering with the experiment.

\subsection{Research Design}

We used parametric statistics (i.e., Repeated Measures ANOVA and Paired-Samples T-Test), prior assumptions' verification. In order to ensure certain degree of robustness to outlying observation, we used further nonparametric tests (i.e., Mann-Whitney $U$ for independent samples, Friedman Test and Wilcoxon signed ranks test for related samples). For comparisons between subgroups where sample size was halved (i.e., presentation modality, gender), we just used nonparametric tests. For multiple comparisons the nominal significance level $(p<.05)$ was corrected applying Bonferroni’s procedure, i.e. when all 20 clips were compared it was set at $p<.0001$.

\section{Analysis and Results}

In order to examine whether all clips could elicit all emotions with the same effectiveness, or instead any clip was emotion-specific, three criteria were considered: the intensity of emotional activation, the effect of plots' 
clarity and moods' comprehension, and the specificity of the profile of emotional responses.

\subsection{Clips' Notoriety}

As listed in Table 1, four clips were never been seen on cinema, television or web sites in our sample (Hannah, Golden, Crimes, and Maria). For the other clips, the percentage of notoriety ranged from $3.1 \%$ for Pink and Killing, to $75 \%$ for Silence. We found that in Officer 1 mood pleasantness was significantly higher when clip had been already seen $\left(M_{1}=5.47, S D_{1}=1.01 ; M_{2}=6.33, S D_{2}=1.47\right)$, Mann-Whitney $U=62, n_{1}=17, n_{2}=15$, $p<.01$. These results suggest that the notoriety of clips can only marginally influence the emotional activation, suggesting us to get focused on specific emotional profiles elicited by clips.

\subsection{Overall Dimensions: Mood Pleasantness, Mood Intensity, Plots and Characters Comprehension}

With regard to pleasantness and intensity, assessed as broad dimensions, we didn't find any significant differences between presentation modalities (for all comparisons, $p s>.01$ ). Mean values and standard deviations are showed in Table 2. We tested whether there were significant differences between film clips; since the independent variable (i.e., videoclip) had 20 related groups, we used statistical testing for repeated measures.

Mauchly's Test of Sphericity suggested to reject the null hypothesis that the variances of the differences were equal (for mood pleasantness: $\chi^{2}(189)=253.64, p<.005$; for mood intensity: $\chi^{2}(189)=255.96, p<.005$ ), so the

Table 2. Descriptive statistics of dimensions of mood pleasantness, mood intensity, plot's clarity and characters’ feelings. Differences between clip discussed in the text.

\begin{tabular}{|c|c|c|c|c|c|}
\hline \multirow{2}{*}{ Emotion } & \multirow{2}{*}{ Clip } & \multicolumn{4}{|c|}{ Mean (SD) } \\
\hline & & Pleasantness & Intensity & Plot & Characters \\
\hline \multirow[t]{3}{*}{ Amusement } & Golden & 5.69 (1.09) & 3.75 (1.85) & $1.72(1.05)$ & $3.09(0.82)$ \\
\hline & Officer 1 & $5.88(1.1)$ & 4.19 (1.47) & $2.63(1.1)$ & $3.16(0.92)$ \\
\hline & Harry & $5.69(0.97)$ & $4.84(1.14)$ & $2.69(1.12)$ & 3.09 (0.73) \\
\hline \multirow[t]{4}{*}{ Anger } & Gandhi & 2.69 (1.45) & 3 (1.59) & $2(1.16)$ & $2.53(0.92)$ \\
\hline & Witness & $2.28(1.33)$ & 3.31 (1.75) & $2.31(1.18)$ & 2.81 (1.03) \\
\hline & Cry & $0.53(0.88)$ & 6 (1.19) & $2.38(0.87)$ & $2.78(1.04)$ \\
\hline & Bodyguard & 1.09 (1.25) & $4.81(1.4)$ & $2.06(0.98)$ & $2.5(0.95)$ \\
\hline \multirow[t]{3}{*}{ Disgust } & Godfather & 1.25 (1.19) & 4.47 (1.7) & 1.75 (1.46) & 3.19 (0.69) \\
\hline & Maria & $1.06(1.19)$ & $4.75(1.52)$ & $0.75(0.72)$ & $2.06(1.13)$ \\
\hline & Pink & $0.97(1.56)$ & 5.13 (2.09) & $1.03(1.23)$ & $1.03(1.12)$ \\
\hline \multirow[t]{3}{*}{ Fear } & Silence & $1.94(1.34)$ & $4.44(1.81)$ & $2.56(1.05)$ & $3.03(0.9)$ \\
\hline & Halloween & $1.06(1.16)$ & $5.13(1.58)$ & $1.97(1.23)$ & $3.03(0.9)$ \\
\hline & Marathon & $0.97(1.18)$ & $5.44(1.37)$ & $2.25(1.16)$ & $3.16(0.88)$ \\
\hline \multirow[t]{3}{*}{ Sadness } & Officer 2 & $1(1.08)$ & $4.56(1.61)$ & $2.19(1.03)$ & $3.09(0.82)$ \\
\hline & Killing & $1.75(1.27)$ & 3.53 (1.98) & $1.16(1.02)$ & $2.66(1.12)$ \\
\hline & Champ & 1.19 (1.03) & $4.34(1.41)$ & $2.63(0.83)$ & $3.09(0.78)$ \\
\hline \multirow[t]{4}{*}{ Neutral } & Hannah & $3.25(.92)$ & $1.34(1.23)$ & $1.94(0.67)$ & $2.19(0.78)$ \\
\hline & Emperor & $3(1.05)$ & $1.38(1.18)$ & $1.03(0.82)$ & $1.13(0.83)$ \\
\hline & Crimes & $2.84(1.27)$ & 1.5 (1.44) & $0.88(0.98)$ & 1.38 (1.04) \\
\hline & President & 3.09 (1.09) & $1.13(1.18)$ & $0.91(0.93)$ & $0.97(0.93)$ \\
\hline
\end{tabular}


Greenhouse-Geisser Correction was used to correct the degrees of freedom of the F-distribution. Repeated Measures ANOVA showed that comparisons were significant: for mood pleasantness, $F(10.37,321.55)=80.26, p$ $<.001$; for mood intensity, $F(9.32,288.97)=39.02, p<.001$. Nonparametric Friedman Tests confirmed the results (for both, $p s<.001$ ).

More specifically, for mood pleasantness, Officer 1, Harry and Golden obtained the highest scores; they did not differ significantly each other ( $p s>.3$ ), but all three differed significantly from the following higher clip, Hannah ( $p s$ <.001), suggesting they could represent "absolutely positive" film clips. Interestingly, the group of the lowest clips seemed not to be homogeneous, since the lowest clip, Cry, was significantly less intense in mood pleasantness than Silence and Killing ( $p s<.001)$.

For mood intensity, the lowest values were in order President, Hannah, Crimes and Emperor. They didn't differ significantly each other ( $p s>.1$ ), but all them differed significantly from the following lowest clip, Gan$d h i$ ( $p$ s <.001): these four clips most likely could be considered the neutral ones. Cry showed the highest value: it was significantly different from Bodyguard, $t(31)=4.266, p<.001$, but not from the other clips with elevated intensity, Halloween, Pink, and Marathon (ps > .01).

For plots' and characters' understanding, all clips showed satisfactory scores (i.e., mean value greater than 1), as reported in Table 2. Only Maria and two of the expected neutral films, Crimes and President, obtained low scores for plot's clarity; moreover, for President subjects reported difficulties in empathize with characters. There was a significant difference between presentation modalities only for Gandhi comprehension of characters' feelings (without sound: $M=2, S D=.63$; with sound: $M=3.06, S D=.85$ ), Mann-Whitney $U=45.5, n_{1}=n_{2}=$ $16, p<.005$.

In order to understand the relationships between pleasantness, intensity, plots' clarity and moods' comprehension, we computed the overall mean values for each variables as averages between clips. Controlling for gender, age, and presentation modality, the mean value of plots' clarity correlated with the mean value of moods' comprehension, $r_{\text {partial }}=.615, p<.001$. Variables were no more significantly related each other $(p s<.2)$.

\subsection{Emotions: Differences between Clips and within Clips}

We evaluated the scores of the clips according to the intensity of each target emotion. Moreover, since different clips could elicit different emotions' profiles, even if target emotion is expected to be the same one (Rottenberg et al., 2007), we tested if the values of higher emotions where significantly different from the secondary emotions; we compared the results obtained in our Italian sample with Hewig's findings. Table 3 summarizes Hewig's results and the ones. We considered the differences depending on the presentation modality (sound vs. no sound).

Amusement. The comparison of our results with those of the German study as to the intensity of each emotion shows that the overall group of positive emotions (serenity, amusement, happiness) is elicited by the same clips, that is Harry, Golden and Officer 1. For serenity and happiness these clips were interchangeable ( $p s>.1)$. For amusement, on the other hand, Harry was significantly higher than Golden, $t(31)=-4.774, p<.001$, and Officer 1, $t(31)=-7.048, p<.001$; also, Golden was higher than Officer $1, t(31)=-3.405, p<.001$. Only Harry elicited amusement stronger than happiness, $t(31)=4.023, p<.001$ and serenity, $t(31)=6.281, p<.001$. It is important to note that if Harry is presented in the version with sound the emotions elicited are stronger than in the mute version for all three emotions ( $p s<.05$ ).

Anger. In Hewig and colleagues' article (2005) and in our study the clips eliciting anger are the same ones (Cry, Bodyguard, Witness and Gandhi). We found that for anger, Cry and Bodyguard were not significantly different, $t(31)=2.208, p>.01$, and both were higher than Witness ( $p$ s $<.001)$. We assessed also indignation as a moderate form of rage: the highest clips were again Cry, Bodyguard, and Witness, each one of them significant different from the other two ( $p s<.005)$. Indignation's and anger's scores distributions overlapped in Cry, $t(31)$ $=2.273, p>.025$, in Witness, $t(31)=2.121, p>.04$, and in Bodyguard, $t(31)=1, p>.2$; however, Gandhi elicited indignation more than anger, $t(31)=2.955, p<.01$, suggesting that this clip may be qualitatively different from the other three. In the German study, the secondary emotion was sadness, significantly lower than rage only for Bodyguard and Witness. We found that sadness was significantly lower than indignation in Gandhi (M $=1.5, S D=1.74), t(31)=4.766, p<.001$, and Witness $(M=1.03, S D=1.4), t(31)=8.004, p<.001$, and it was lower than anger in Bodyguard $(M=2.75, S D=1.98), t(31)=7.627, p<.001$. The profile of Cry is discussed below. A significant difference between presentation conditions was found for anger in Gandhi (without sound: $M=1.63, S D=2.13$; with sound: $M=3.31, S D=2.12$ ), Mann-Whitney $U=74.5, n_{1}=n_{2}=16, p<.05$. 
Table 3. Emotions’ profile within clips in the German study (Hewig et al., 2005) and the present research.

\begin{tabular}{|c|c|c|c|c|}
\hline \multirow{2}{*}{$\begin{array}{l}\text { Target } \\
\text { emotion }\end{array}$} & \multicolumn{2}{|c|}{ Hewig et al., $2005(N=38)$} & \multicolumn{2}{|c|}{ Present study $(N=32)$} \\
\hline & $\begin{array}{l}\text { Film clips with highest } \\
\text { target emotion }\end{array}$ & $\begin{array}{l}\text { Clips' secondary } \\
\text { emotion(s) }\end{array}$ & $\begin{array}{l}\text { Film clips with } \\
\text { highest target emotion }\end{array}$ & Clips' secondary emotion(s) \\
\hline \multirow{3}{*}{ Amusement } & $\begin{array}{c}\text { Harry } \\
\text { (Amusement) }\end{array}$ & \multirow{3}{*}{ [not reported] } & $\begin{array}{l}\text { Harry (Amusement: } \\
M=5.94, S D=0.98 \text { ) }\end{array}$ & $\begin{array}{l}\text { Happiness }(M=5, S D=1.46)^{* *} \\
\text { Serenity }(M=4.53, S D=1.61)^{* *}\end{array}$ \\
\hline & $\begin{array}{l}\text { Officer } 1 \\
\text { (Pleasure) }\end{array}$ & & $\begin{array}{l}\text { Golden (Happiness: } \\
M=5.06, S D=1.58 \text { ) }\end{array}$ & $\begin{array}{c}\text { Serenity }(M=4.75, S D=1.59) \\
\text { Amusement }(M=4.69, S D=1.51)\end{array}$ \\
\hline & $\begin{array}{l}\text { Golden } \\
\text { (Pleasure) }\end{array}$ & & $\begin{array}{l}\text { Officer } 1 \text { (Serenity: } \\
M=4.97, S D=1.58)\end{array}$ & $\begin{array}{c}\text { Happiness }(M=4.53, S D=1.8) \\
\text { Amusement }(M=3.41, S D=1.62)\end{array}$ \\
\hline \multirow{4}{*}{$\begin{array}{l}\text { Anger/ } \\
\text { Rage }\end{array}$} & Cry & Sadness & $\begin{array}{c}\text { Cry (Indignation: } \\
M=6.47, S D=1.02)\end{array}$ & $\begin{array}{c}\text { Anger }(M=5.97, S D=1.51) \\
\text { Sadness }(M=5.47, S D=1.97)^{\wedge}\end{array}$ \\
\hline & Bodyguard & Sadness ${ }^{* *}$ & Bodyguard (Anger: $M=5.38, S D=1.86$ ) & Indignation $(M=5.09, S D=1.94)$ \\
\hline & Gandhi & Sadness & Witness (Indignation: $M=3.75, S D=2.4$ ) & Anger $(M=3.16, S D=2.7)$ \\
\hline & Witness & Sadness $^{* *}$ & $\begin{array}{l}\text { Gandhi (Indignation: } \\
M=3.41, S D=2.64 \text { ) }\end{array}$ & $\begin{array}{l}\text { Surprise }(M=2.91, S D=2.02) \\
\text { Anger }(M=2.47, S D=2.26)^{\wedge}\end{array}$ \\
\hline \multirow{3}{*}{ Disgust } & Pink & Amusement $^{* *}$ & $\operatorname{Pink}(M=6.5, S D=1.24)$ & Surprise $(M=4.63, S D=2.38)^{* *}$ \\
\hline & Maria & Fear $^{* *}$ & Maria $(M=5.38, S D=1.83)$ & Tension $(M=3.94, S D=1.48)^{* *}$ \\
\hline & Godfather & Fear $^{* *}$ & $\begin{array}{c}\text { Godfather } \\
(M=5.03, S D=2.06)\end{array}$ & $\begin{array}{c}\text { Fear }(M=3.28, S D=2.2)^{* *} \\
\text { Surprise }(M=3.13, S D=1.93)^{*} \\
\text { Tension }(M=3.13, S D=2.35)^{*}\end{array}$ \\
\hline \multirow{3}{*}{ Fear } & Halloween & Disgust $^{* *}$ & Halloween (Tension: $M=5.41, S D=1.41$ ) & Fear $(M=4.88, S D=1.74)$ \\
\hline & Silence & Disgust $^{* *}$ & $\begin{array}{l}\text { Marathon (Tension: } \\
M=5.22, S D=1.45 \text { ) }\end{array}$ & $\begin{array}{c}\text { Fear }(M=4.16, S D=2.34)^{*} \\
\text { Disgust }(M=3.94, S D=2.23)^{*}\end{array}$ \\
\hline & Marathon & Disgust & Silence (Tension: $M=4.88, S D=1.45$ ) & Fear $(M=3.66, S D=2.09)^{* *}$ \\
\hline \multirow{4}{*}{ Sadness } & Cry & Rage & $\operatorname{Cry}(M=5.47, S D=1.97)$ & Anger $(M=5.97, S D=1.51)$ \\
\hline & Champ & Rage $^{* *}$ & Officer $2(M=5.28, S D=1.59)$ & Surprise $(M=2.5, S D=2.13)^{* *}$ \\
\hline & Killing & Rage $^{* *}$ & Champ $(M=5.09, S D=1.73)$ & Tension $(M=1.97, S D=1.64)^{* *}$ \\
\hline & Officer 2 & Disgust $^{* *}$ & Killing $(M=4.44, S D=1.56)$ & Tension $(M=2.09, S D=1.92)^{* *}$ \\
\hline Surprise & \multicolumn{2}{|c|}{ [not assessed] } & $\operatorname{Pink}(M=4.63, S D=2.38)$ & Disgust $(M=6.5, S D=1.24)^{* *}$ \\
\hline \multirow{4}{*}{$\begin{array}{l}\text { Neutral } \\
\text { Clips }\end{array}$} & Emperor (Pleasure) & & Hannah (Serenity: $M=2.5, S D=1.88$ ) & Amusement $(M=1.31, S D=1.51)^{*}$ \\
\hline & Crimes (Happiness) & & Emperor (Serenity: $M=2.22, S D=1.6$ ) & Amusement $(M=0.69, S D=1.28)^{* *}$ \\
\hline & Hannah (Pleasure) & [not reported] & President (Serenity: $M=2.06, S D=1.44$ ) & Surprise $(M=0.66, S D=1.18)^{* *}$ \\
\hline & $\begin{array}{c}\text { President } \\
\text { (Amusement) }\end{array}$ & & $\begin{array}{l}\text { Crimes (Serenity: } \\
M=1.78, S D=2.03 \text { ) }\end{array}$ & $\begin{array}{l}\text { Tension }(M=1.66, S D=2.01) \\
\text { Surprised }(M=1.03, S D=1.6)\end{array}$ \\
\hline
\end{tabular}

Differences between target and secondary emotion(s): ${ }^{\wedge} p<.01 ;{ }^{*} p<.005 ;{ }^{* *} p<.001$.

Disgust. The emotion of disgust was mainly elicited in the German study by Pink, Maria's Lovers and Godfather, respectively. In our study, Pink's score was the highest one, since its difference with the second higher clip, Maria, was significant, $t(31)=4.133, p<.001$. In the German study, the second emotion for Godfather and Maria was fear, while in our study they were tension and fear. We found that for each clip disgust was significantly higher than the secondary emotion: surprise for Pink, $t(31)=4.267, p<.001$; tension for Maria, $t(31)=$ 4.281, $p<.001$; fear, surprise and tension for Godfather ( $p s<.001)$. 
Fear. The emotion of fear was mainly elicited by Halloween, Silence and Marathon respectively in the German study. In our study the highest clip was Halloween, but it was not higher than Marathon, $t(31)=-2.174, p$ $<.03$; the third clip, Silence, was different from Halloween, $t(31)=4.673, p<.001$, but not from Marathon, $t(31)$ $=1.403, p<.1$. In the German study the second emotion elicited in all the clips was disgust, and only for Halloween and Silence it was significantly lower than fear. We added tension to emotions' list: the highest scores were found in Halloween, Marathon and Silence, which were not significantly different each other $(p s<.05)$, but the next clip, Maria $(M=3.94, S D=1.48)$, was from all three $(p s<.001)$. Tension was higher than fear in Marathon, $t(31)=3.316, p<.005$, and Silence, $t(31)=5.25, p<.001$; in Halloween, even though tension has a mean value greater than fear, the difference was not significant, $t(31)=1.805, p>.05$.

Sadness. Our study and the German one are partially comparable for the emotion of sadness. In the German study the intensity order was Champ, Killing and Officer 2, while in our study the highest values were in Cry, Officer, Champ, and they didn't differ significantly each other ( $p s>.4)$. We found that Killing was only marginally lower than Cry, $t(31)=-2.738, d f=31, p=.01$, but it was not significantly lower than Officer 2 and Champ ( $p s>.01$ ). In the German study, the second emotion elicited by Officer 2 was disgust, while in our study the second emotion was surprise $(M=2.5, S D=2.13$ ), significantly lower than sadness, $t(31)=5.94, p<.001$, with disgust reported at a very low intensity $(M=.88, S D=1.68)$. In the German study the second emotion was anger both for Champ and Killing, while in our study they elicited tension at a very low level, significantly less intense than sadness: for Champ, $t(31)=7.56, p<.001$; for Killing, $t(31)=6.938, p<.001$. Hewig suggested not to use Cry because it was able to elicit in the same way both sadness and rage; in our study Cry elicited sadness, and the values of indignation and anger were higher than sadness, too, although the difference was marginally significant only for indignation, $t(31)=2.924, p<.01$.

Surprise. Pink was the highest clip, since the difference with Godfather $(M=3.13, S D=1.93)$ was significant, $t(31)=3.375, p<.005$.

Neutral clips. Four clips were considered neutral at first: they should had mild positive valence and quite low intensity: Hannah, Crimes, Emperor, and President. Emperor occupied an intermediate position in mood pleasantness and in serenity, suggesting it could elicit a moderate sense of well-being. Moreover, even if it was close to the other so-called neutral clips for low mood intensity, it showed the highest value among them, suggesting it could be the less boring. Unfortunately, Crimes and President obtained very low scores on plot's clarity, while Emperor was more satisfactory, as showed in Table 2. Hannah, Emperor and President elicit serenity significantly stronger than the secondary emotion, that is respectively amusement $(t(31)=3.221, p<.005)$, amusement again, $t(31)=4.73, p<.001$, and surprise, $t(31)=4.527, p<.001$; in Crimes, instead, serenity and tension didn't differ significantly, $t(31)=.231, p>.7$.

\subsection{Emotions: Reciprocal Relations}

An important point to be taken into consideration is about the way emotions tend to be related each other. The profile of correlations between the emotions assessed with the self-report questionnaire was depicted by partial correlations, adding the effects of subjects' age and gender, and presentation modality (i.e., with or without sound) as constant variables. All emotions correlated significantly each other, with the exception of surprise with serenity, amusement, happiness, sadness and tension ( $p s>.001)$.

To detect the strongest associations between emotions, we tested regression models, in which each emotion was in turn considered the dependent variable, while the independent variables were all the emotions significantly associated with it; the stepwise method was used for choosing the true predictive variables. The effects of subjects' age and gender, and presentation modality were kept constant. Table 4 summarizes the regression analysis results.

These results suggest that it is necessary to consider the relationships between emotions in order to answer our question about videoclips' specificity as emotional stimuli. Consequently, to evaluate whether the mean values of any target emotion are equal across the different clips, it should be tested previously whether this difference could be explained partially or completely by the action of other emotions-that is, we test the homogeneity of regression. If these "confounding emotions" are only partially influencing the relation between the target feeling and the stimuli, an ANCOVA could be performed, controlling for these effects by adding them as covariates.

The homogeneity of regression analysis showed that the interactions between the covariate and the factor (i.e., videoclip) in the prediction of the target emotion were significant for some emotions: the results are listed in Table 4. 
Table 4. Emotions: reciprocal relations.

\begin{tabular}{|c|c|c|c|c|c|}
\hline \multirow{2}{*}{ Emotions } & \multicolumn{2}{|c|}{ Regression analysis } & \multicolumn{3}{|c|}{ Homogeneity of regression ${ }^{a}$} \\
\hline & Positive predictive variables & Negative predictive variables & $F$ & df & $p$ \\
\hline Serene & $\begin{array}{l}\text { Happy }\left(\beta=.471^{* * *}\right) \\
\text { Amused }\left(\beta=.18^{* * *}\right)\end{array}$ & $\begin{array}{c}\text { Disgusted }\left(\beta=-.176^{* * *}\right) \\
\text { Tense }\left(\beta=-.133^{* * *}\right) \\
\text { Sad }\left(\beta=-.093^{* * *}\right)\end{array}$ & 1.842 & 16 & .023 \\
\hline Amused & $\begin{array}{c}\text { Happy }\left(\beta=.768^{* * *}\right) \\
\text { Serene }\left(\beta=.13^{* * *}\right)\end{array}$ & $\operatorname{Sad}\left(\beta=.057^{*}\right)$ & 6.469 & 16 & .000 \\
\hline Happy & $\begin{array}{l}\text { Amused }\left(\beta=.68^{* * *}\right) \\
\text { Serene }\left(\beta=.276^{* * *}\right)\end{array}$ & & 3.285 & 16 & .000 \\
\hline Angry & $\begin{array}{c}\text { Indignant }\left(\beta=.707^{* * * *}\right) \\
\text { Sad }\left(\beta=.188^{* * * *}\right) \\
\text { Tense }\left(\beta=.12^{* * *}\right)\end{array}$ & & 4.542 & 15 & .000 \\
\hline Indignant & $\begin{array}{c}\text { Angry }\left(\beta=.66^{* * *}\right) \\
\text { Disgusted }\left(\beta=.276^{* * *}\right) \\
\text { [Surprised }(\beta=.054)]\end{array}$ & $\begin{array}{l}\text { Scared }\left(\beta=-.106^{* * *}\right) \\
\text { Serene }\left(\beta=-.079^{* *}\right)\end{array}$ & $\begin{array}{c}\text { Angry: } 3.237 \\
\text { Disgusted: } 2.898\end{array}$ & 15 & .000 \\
\hline Disgusted & $\begin{array}{c}\text { Indignant }\left(\beta=.475^{* * * *}\right) \\
\text { Scared }\left(\beta=.28^{* * * *}\right) \\
\text { Surprised }\left(\beta=.183^{* * * *}\right)\end{array}$ & $\begin{array}{c}\text { Serene }\left(\beta=-.192^{* * *}\right) \\
\operatorname{Sad}\left(\beta=-.138^{* * *}\right)\end{array}$ & $\begin{array}{c}\text { Indignant: } 2.146 \\
\text { Scared: } 1.745\end{array}$ & 18 & .004 \\
\hline Scared & $\begin{array}{c}\text { Tense }\left(\beta=.69^{* * * *}\right) \\
\text { Disgusted }\left(\beta=.235^{* * *}\right) \\
\text { Surprised }\left(\beta=.071^{*}\right)\end{array}$ & Indignant $\left(\beta=-.132^{* * *}\right)$ & 2.063 & 15 & .010 \\
\hline Tense & $\begin{array}{l}\text { Scared }\left(\beta=.651^{* * *}\right) \\
\text { Angry }\left(\beta=.132^{* * *}\right)\end{array}$ & $\begin{array}{l}{[\text { Serene }(\beta=-.103)]} \\
{[\text { Happy }(\beta=-.095)]}\end{array}$ & Scared: 5.415 & 15 & .000 \\
\hline Sad & Angry $\left(\beta=.455^{* * *}\right)$ & $\begin{array}{c}\text { Serene }\left(\beta=-.189^{* * *}\right) \\
\text { Disgusted }\left(\beta=-.129^{* * *}\right) \\
\text { [Amused }(\beta=-.11)]\end{array}$ & 4.123 & 16 & .000 \\
\hline Surprised & Disgusted $\left(\beta=.319^{* * *}\right)$ & & 1.177 & 16 & .282 \\
\hline
\end{tabular}

${ }^{\mathrm{a}}$ Significant only with positive predictors; ${ }^{* * *} p<.001 ;{ }^{* *} p<.005 ;{ }^{*} p<.01 ;[] p<.03$.

Surprise. The homogeneity of regression assumption was respected only for surprise, $F(16)=1.117, p>.2$, so ANCOVA can be conducted. The difference between clips remained significant, even when controlling for the effect of disgust, $F(19,69)=6.907, p<.001$. Previous tests showed that Pink Flamingos was the most effective videoclip in eliciting surprise, although disgust was higher than surprise.

For the other emotions, the homogeneity of regression assumption had been violated, that is, the effect of the videoclips could never be distinguished from the effect of related emotions $(p<.05)$.

Disgust. The homogeneity of regression test showed that the effect of disgust couldn't be clearly distinguished from indignation, $F(18)=2.146, p<.005$, and only marginally from fear, $F(15)=1.745, p<.05$, in our clips' set. Anyway, the clip with the highest value in disgust, Pink Flamingos, had low values in indignation ( $M$ $=3.14, S D=2.54)$ and in fear $(M=0.13, S D=0.55)$, and the correlations between these two emotions and disgust were not significant (for indignation: $r_{\text {partial }}=.227, p=.236$; for fear: $r_{\text {partial }}=.085, p=.66$ ).

Serenity, amusement, happiness. Officer 1, Golden and Harry had obtained the highest mean scores in serenity, amusement and happiness, confirming their expected positive valence. Since for each one of these three emotions the effect of the videoclips can never be distinguished from the effect of the other two emotions, a global index of "Positive Emotion" was computed as mean value: first positions in intensity were occupied by Harry $(M=5.16, S D=1.13)$, Golden $(M=4.83, S D=1.35)$ and Officer $1(M=4.3, S D=1.31)$, resembling the same result obtained for mood pleasantness dimension. The three clips didn't differ significantly each other ( $p s>.1)$, but they were all higher than the following clip, Hannah $(M=1.49, S D=1.1 ; p s<.001)$.

Fear, tension. The same happened to fear and tension. The homogeneity of regression test showed that the 
effect of fear couldn't be clearly distinguished from tension, $F(15)=5.415, p<.001$, in our clips' set. We computed another global index as mean of the values, called "Tense Emotion". The highest values were: Halloween $(M=5.14, S D=1.35)$, Marathon $(M=4.69, S D=1.73)$, Silence $(M=4.27, S D=1.68)$, and Maria $(M=3.69$, $S D=1.51)$. Halloween was not different from Marathon, $t(31)=1.625, p>.1$, but it was from Silence, $t(31)=$ 3.917, $p<.001$, and Maria, $t(31)=6.735, p<.001$. Marathon was comparable with Silence, $t(31)=1.408$, $p>.1$, but it was significantly higher than Maria, $t(31)=3.231, p<.005$; Silence and Maria didn't differ significantly each other, $t(31)=2.145, p>.03$.

Sadness, anger, indignation. Sadness, anger, and indignation showed interesting reciprocal relationships. The homogeneity of regression assumption had been violated $(p<.001)$, so we decided to evaluate carefully the correlations between them within each videoclip, keeping constant the effects of age, gender and presentation modality. The emotions had significant reciprocal associations in Gandhi, Witness, Bodyguard, Godfather, Maria, Silence, Halloween and Marathon ( $p<.05)$ : these clips seemed to elicit various strong negative affects in the "anger realm", and relations between them were not fully clear.

In Officer 2 and in Killing, a significant correlation between anger and indignation was found ( $p s<.005$ ), but their association with sadness was not significant ( $p s>.03$ ); moreover, Officer 2 showed a very low value in anger $(M=0.84, S D=1.67)$ and in indignation $(M=0.94, S D=1.58)$, and very high in sadness.

For Cry and Pink, significant correlations were found between anger and indignation ( $p$ s < .005), and between anger and sadness ( $p s<.001)$, but not between sadness and indignation ( $p s>.05)$. In particular, Cry Freedom showed elevated mean values for all three emotions, as presented in Table 3; anyway, while almost all subjects had high values on indignation in this clip (range: 3 - 7), the scores' distribution of sadness could range from low to intermediate values (range: 0 - 7). These results seemed to suggest that the stronger were the sadness feelings elicited by Cry Freedom, the higher was another negative emotion, anger, but that it could be very low when the emotional involvement was more detached — that is, when indignation was high and anger was low.

\section{Discussion}

The main aim of this study was to replicate the study by Hewig et al. (2005), where a new set of emotional clips was selected, in a different cultural context. Indeed we considered that the effect of cultural variables could undermine the validity of the results obtained in Germany, when utilized in Italy.

First of all, we tested some aspects concerning the way of administration, and clips' notoriety. Only for few clips (Harry for serene, happy and amused; Hannah for amused; Gandhi for angry) the administration with sound showed a more intense emotional reaction. The presentation with sound enhanced comprehension of characters' feelings just in Gandhi, not in the other clips; no influence was found for plot's clarity. In summary, presentation modality seemed not to influence clips' emotional profile.

The notoriety of clips had just a small effect on emotional activation, since only mood pleasantness of Officer 1 and plot's comprehension of Silence were higher when clip had been already seen. On the other side, the presence of disturbing elements was very low for every videoclip, and not affected by presentation modalities; the detection of disturb elements is related to low intensity and poor comprehension, but it is not altered by negative emotionality or boredom - that is, it is easiest with the neutral or almost neutral clips.

In emotions' assessment, especially when using films, it is important to have stimuli able to elicit specific emotions: in fact, films vary greatly in their thematic complexity (Gross \& Levenson, 1995). Overall, our research confirmed the results obtained by the German researchers who showed that it was possible to select a set of clips eliciting target emotions (amusement, sadness, anger, fear/tension, disgust, and neutral). One of the most important problems is the capacity of the clips to really elicit single, that is pure, emotions.

The results for the "amusement" clips are fully comparable to those of the German study, showing that Harry, Golden and Officer 1 significantly elicit the highest positive emotions. If Golden and Officer 1 elicit amusement, serenity and happiness almost in the same way, Harry elicits amusement more than happiness. When we considered the results on pleasantness, we discovered that these clips were the best performers also in this area. Our results suggest that it is quite difficult to differentiate positive emotions each other, as reported by Ellsworth \& Smith (1988).

Pink elicits disgust to a high degree, according to the German results. However, the secondary emotion in the Italian study is surprise and in the German one it was amusement. Pink also elicits surprise to the highest degree. The emotion of surprise, that we considered according to Ekman's (1972) and Izard (1991) list of basic emo- 
tions and was not taken into consideration in the German study, seems not having a clear positive or negative valence, but appears in some way related to different emotions (disgust, sadness, indignation) and also to serenity for neutral clips. This is in agreement with Izard's conceptualization of surprise as a basic, but anomalous emotion, a rapidly passing, often mildly pleasant feeling with little thought content, elicited by any sudden and unexpected event (Izard, 1991).

The emotion of fear is elicited at the highest degree by Halloween, Marathon and Silence. More precisely, they elicit fear and tension in Halloween, while tension is more intense than fear in Silence and Marathon. If the selected clips are the same in the two studies, we found differences in the secondary emotions: where the German study found disgust we found fear, except for Marathon were disgust was significantly lower in the German study and only marginally lower in our study. It is possible that the similarities are more than the differences because we separated the emotions of fear and of tension. Tension was of interest because it is the most diffused emotional state in United States and perhaps in the Western world (Mesquita \& Karasawa, 2000) and we were involved in checking the role of emotional tension that, although it is most frequently discussed and investigated with respect to its negative aspects, which are subjectively experienced as distress, fear, or pathological anxiety, also has positive effects, enabling an individual to overcome various obstacles, and thus plays a positive role in the adaptive process (Rotenberg, 1984). Moreover, we also considered emotional tension important for our research in personality disorders, according to the fact that an intense state of unbearable tension, called "aversive tension" seems to play an important role in provoking dissociative states and self-injuring impulsive behaviour in borderline subjects (Stiglmayr et al., 2005).

As to the emotion of sadness, Officer 2, Champ and Killing are the clips that selectively elicit it. We found differences in the secondary emotions, indeed Officer 2 elicits disgust in the German study and surprise in ours, while Champ and Killing elicit rage in the German study and tension in ours. Rage is elicited by the same four clips, that is Crime, Bodyguard, Witness and Gandhi. All these clips elicit in the same way both anger and indignation, but Bodyguard is higher in anger and the others in indignation. The secondary emotion in the German study is sadness, and the difference is significant only for Bodyguard and Witness. In our study, the profiles are more complex: Bodyguard and Witness seem to elicit only the pair represented by rage and indignation, while Gandhi also elicits high surprise. Finally, Cry elicits indignation and anger, also sadness, in a marginally lower intensity than indignation, but not anger. To summarise, the German and the Italian study show very similar results with regard to the primary emotions elicited, but they show some differences in the secondary emotions. An important role in that is played by the emotions of surprise and tension that are not evaluated in the German study.

Concerning the emotionally neutral clips, the two studies were completely comparable. We also wanted to check the role of the sound and of the gender, that were not considered in the German study: for some clips (Harry for serene, happy and amused; Hannah for amused; Gandhi for angry) the administration with sound shows a more intense emotional reaction. Finally, there are some differences depending on gender: Harry, Cry and Maria for surprised, where males show more intense reactions, and Halloween and Silence for scared, where females are more intensely activated.

Starting from the fact that it is possible to select clips that elicit single emotions in a significant way, the fact that all the clips elicited more than one emotion suggested us to control if there were correlations among the emotions. This is important because there are some aspects of the theory of emotions that are still controversial: they concern the contrast between the universal theories of emotion, suggesting that individuals are born hardwired to experience the basic emotions (Ekman, Levenson, \& Friesen, 1983; Tomkins \& McCarter, 1964) and theories giving importance to cultural factors on the experience and the expression of the emotions (Russell, 1995).

We found significant correlations with few exceptions and the regression models, tested to find the most important correlations, showed that it was possible to identify a pattern of positive emotions (amusement, serenity and happiness), and complex patterns of negative emotions: sadness is correlated only with anger, but anger is correlated with indignity and tension, indignity is also correlated with disgust, and tension is correlated with fear, that is in turn correlated with disgust and surprise; disgust is also correlated with fear. Even if our study started from an implicit universalist statement, with some interest in finding cultural differences more linked to immediate research needs (that is comparing clinical and non-clinical populations avoiding possible effects of cultural factors) than to theory, these results could be also interpreted from a cultural perspective. Indeed, even if basic emotions do exist, their "patterning" (Middleton, 1989) could be strongly conditioned by culture. 


\section{Conflicts of Interests}

The authors declare no conflict of interest.

\section{References}

Boiten, F. A. (1998). The Effects of Emotional Behaviour on Components of Respiratory Cycle. Biological Psychology, 49, 29-51. http://dx.doi.org/10.1016/S0301-0511(98)00025-8

Bradley, M. M., \& Lang, P. J. (2007). The International Affective Picture System (IAPS) in the Study of Emotion and Attention. In J. A. Coan, \& J. J. B. Allen (Eds.), Handbook of Emotion Elicitation and Assessment (pp. 29-46). London: Oxford University Press.

Bradley, M. M., Hamby, S., Low, A., \& Lang P. J. (2007). Brain Potentials in Perception: Picture Complexity and Emotional Arousal. Psychophysiology, 44, 364-373. http://dx.doi.org/10.1111/j.1469-8986.2007.00520.x

Bruder, M., Dosmukhambetova, D., Nerb, J., \& Manstead, A. S. R. (2012). Emotional Signals in Nonverbal Interaction: Dyadic Facilitation and Convergence in Expressions, Appraisals, and Feelings. Cognition and Emotion, 26, 480-502. http://dx.doi.org/10.1080/02699931.2011.645280

Coan, J. A., \& Allen, J. J. B. (2007). Handbook of Emotion Elicitation and Assessment. London: Oxford University Press.

Darwin, C. (1872/1965). The Expression of the Emotions in Man and Animals. Chicago, IL: University of Chicago.

Davidson, R. J., Goldsmith, H. H., \& Scherer, K. (2003). Handbook of Affective Science. London: Oxford University Press.

Ekman, P. (1972). Universal and Cultural Differences in Facial Expression of Emotions. In J. Cole (Ed.), Nebraska Symposium on Motivation (pp. 207-283). Lincoln: University of Nebraska Press.

Ekman, P., Friesen, W. V., \& Hager, J. C. (2002). The Facial Action Coding System. Salt Lake City, UT: Research Nexus eBook.

Ekman, P., Levenson, R. W., \& Friesen, W. V. (1983). Autonomic Nervous System Activity Distinguishes among Emotions. Science, 221, 1208-1210. http://dx.doi.org/10.1126/science.6612338

Ellsworth, P. C., \& Smith, C. A. (1988). Shades of Joy: Patterns of Appraisal Differentiating Pleasant Emotions. Cognition and Emotion, 2, 301-331. http://dx.doi.org/10.1080/02699938808412702

Fridlund, A. J. (1991). Sociality of Solitary Smiling: Potentiation by an Implicit Audience. Journal of Personality and Social Psychology, 60, 229-240. http://dx.doi.org/10.1037/0022-3514.60.2.229

Frijda, N. H. (1989). Aesthetic Emotions and Reality. American Psychologist, 44, 1546-1547. http://dx.doi.org/10.1037/0003-066X.44.12.1546

Gerrards-Hesse, A., Spies, K., \& Hesse, F. W. (1994). Experimental Induction of Emotional States and Their Effectiveness. A Review. British Journal of Psychology, 85, 55-78. http://dx.doi.org/10.1111/j.2044-8295.1994.tb02508.x

Gross, J. J. (2010). The Future’s so Bright, I Gotta Wear Shades. Emotion Review, 2, 212-216. http://dx.doi.org/10.1177/1754073910361982

Gross, J. J., \& Levenson, R. W. (1995). Emotion Elicitation Using Films. Cognition and Emotion, 9, 87-108. http://dx.doi.org/10.1080/02699939508408966

Gross, J. J., Sutton, S. K., \& Ketelaar, T. (1998). Relations between Affect and Personality: Support for the Affect-Level and Affective-Reactivity Views. Personality and Social Psychology Bulletin, 24, 279-288. http://dx.doi.org/10.1177/0146167298243005

Hagemann, D., Naumann, E., Maier, S., Becker, G., Lu Èrken, A., \& Bartussek, D. (1999). The Assessment of Affective Reactivity Using Films: Validity, Reliability, and Sex Differences. Personality and Individual Differences, 26, 627-639. http://dx.doi.org/10.1016/S0191-8869(98)00159-7

Haidt, J., \& Keltner, D. (1999). Culture and Facial Expression: Open-Ended Methods Find More Expressions and a Gradient of Recognition. Cognition and Emotion, 13, 225-266. http://dx.doi.org/10.1080/026999399379267

Hewig, J., Hagemann, D., Seifert, J., Gollwitzer, M., Naumann, E., \& Bartussek, D. (2005). A Revised Film Set for the Induction of Basic Emotions. Cognition and Emotion, 19, 1095-1109. http://dx.doi.org/10.1080/02699930541000084

Izard, C. E. (1991). The Psychology of Emotions. New York, NY: Plenum Press. http://dx.doi.org/10.1007/978-1-4899-0615-1

Jakobs, E., Manstead, A. S. R., \& Fischer, A. H. (2001). Social Context Effects on Facial Activity in a Negative Emotional Setting. Emotion, 1, 51-69. http://dx.doi.org/10.1037/1528-3542.1.1.51

Kring, A. M., \& Sloan, D. M. (2007). The Facial Expression Coding System (FACES): Development, Validation, and Utility. Psychological Assessment, 19, 210-224. http://dx.doi.org/10.1037/1040-3590.19.2.210

Lang, P. J., Greenwald, M. K., Bradley, M. M., \& Hamm, A. O. (1993). Looking at Pictures: Affective, Facial, Visceral, and 
Behavioral Reactions. Psychophysiology, 30, 261-273. http://dx.doi.org/10.1111/j.1469-8986.1993.tb03352.x

Lazar, J. N., \& Pearlman-Avnion, S. (2014). Effect of Affect Induction Method on Emotional Valence and Arousal. Psychology, 5, 595-601. http://dx.doi.org/10.4236/psych.2014.57070

Mauss, I. B., \& Robinson, M. D. (2009). Measures of Emotion: A Review. Cognition and Emotion, 23, 209-237. http://dx.doi.org/10.1080/02699930802204677

Mauss, I. B., Levenson, R. W., McCarter, L., Wilhelm, F. H., \& Gross, J. J. (2005). The Tie That Binds? Coherence among Emotion Experience, Behavior, and Physiology. Emotion, 5, 175-190. http://dx.doi.org/10.1037/1528-3542.5.2.175

Mesquita, B. (2003). Emotions as Dynamic Cultural Phenomena. In R. Davidson, H. Goldsmith, \& K. R. Scherer (Eds.), Handbook of Affective Science (pp. 871-890). London: Oxford University Press.

Mesquita, B., \& Karasawa, M. (2000). Emotion Words: The Difference between Prototypical Concepts and Daily Experiences. Unpublished Manuscript.

Middleton, D. R. (1989). Emotional Style: The Cultural Ordering of Emotions. Ethos, 17, 187-201. http://dx.doi.org/10.1525/eth.1989.17.2.02a00030

Philippot, P. (1993). Inducing and Assessing Differentiated Emotion-Feeling States in the Laboratory. Cognition and Emotion, 7, 171-193. http://dx.doi.org/10.1080/02699939308409183

Rotenberg, V. S. (1984). Search Activity in the Context of Psychosomatic Disturbances, Sleep of Brain Monoamines and REM Function. Pavlovian Journal of Biological Science, 19, 1-15.

Rottenberg, J., Kasch, K. L., Gross, J. J., \& Gotlib, I. H. (2002). Sadness and Amusement Reactivity Differentially Predict Concurrent and Prospective Functioning in Major Depressive Disorder. Emotion, 2, 135-146. http://dx.doi.org/10.1037/1528-3542.2.2.135

Rottenberg, J., Ray, R. D., \& Gross, J. J. (2007). Emotion Elicitation Using Films. In J. A. Coan, \& J. J. B. Allen (Eds.), The Handbook of Emotion Elicitation and Assessment (pp. 9-28). London: Oxford University Press.

Russell, J. A. (1995). Facial Expressions of Emotion: What Lies beyond Minimal Universality? Psychological Bulletin, 118, 379-391. http://dx.doi.org/10.1037/0033-2909.118.3.379

Russell, J. A. (2003). Core Affect and the Psychological Construction of Emotion. Psychological Review, 110, 145-172. http://dx.doi.org/10.1037/0033-295X.110.1.145

Sato, W., Noguchi, M., \& Yoshikawa, S. (2007). Emotion Elicitation Effect of Films in a Japanese Sample. Social Behavior and Personality, 35, 863-874. http://dx.doi.org/10.2224/sbp.2007.35.7.863

Stiglmayr, C. E., Grathwol, T., Linehan, M. M., Ihorst, G., Fahrenberg, J., \& Bohus, M. (2005). Aversive Tension in Patients with Borderline Personality Disorder: A Computer-Based Controlled Field Study. Acta Psychiatrica Scandinavica, 111, 372-379. http://dx.doi.org/10.1111/j.1600-0447.2004.00466.x

Tomarken, A. J., Davidson, R. J., \& Henriques, J. B. (1990). Resting Frontal Brain Asymmetry Predicts Affective Responses to Films. Journal of Personality and Social Psychology, 59, 791-801. http://dx.doi.org/10.1037/0022-3514.59.4.791

Tomkins, S. S., \& McCarter, R. (1964). What and Where Are the Primary Affects? Some Evidence for a Theory. Perceptual and Motor Skills, 18, 119-158. http://dx.doi.org/10.2466/pms.1964.18.1.119

Wilson, T. D., \& Schooler, J. W. (1991). Thinking Too Much: Introspection Can Reduce the Quality of Preferences and Decisions. Journal of Personality and Social Psychology, 60, 181-192. http://dx.doi.org/10.1037/0022-3514.60.2.181 


\section{Supplementary Material}

In every video clip, as shown in Table S1, at least one subject identified a disturb element, but the mean number of disturb elements detected in all clip was less than one $(M=0.3, S D=0.21)$. Fisher's Exact Probability test showed that the presence of disturbing elements was not significantly more frequent for clips' presentation modalities ( $p s>.1$ ). Correlation analysis indicated that the number of subjects who identified at least one disturb elements was negatively significantly associated with the intensity of the global activation, $r=-.774, p<.001$, characters' comprehension, $r=-.775, p<.001$, and plot's clarity, $r=-.779, p<.001$, but it didn't correlate with mood pleasantness, $r=.11, p=.644$, nor with the length of clips $r=-.454, p=.044$. These results indicate that the presence of disturbing elements can influence the emotional activation in a non-relevant manner.

Table S1. Clips' disturb elements: number and percentage of subjects who identified them.

\begin{tabular}{|c|c|c|}
\hline Emotions & Clips & Disturb elements \\
\hline \multirow[t]{3}{*}{ Amusement } & Golden & 14 (43.8\%): length \\
\hline & Officer 1 & 2 (6.3\%): length, coherence \\
\hline & Harry & 1 (3.1\%): coherence \\
\hline \multirow[t]{4}{*}{ Anger } & Gandhi & 8 (25\%): length, coherence, quality \\
\hline & Witness & 10 (31.3\%): length, coherence, quality \\
\hline & Cry & 4 (12.5\%): length, coherence, quality \\
\hline & Bodyguard & 5 (15.6\%): length, coherence, expressiveness, quality \\
\hline \multirow[t]{3}{*}{ Disgust } & Godfather & 3 (9.4\%): length \\
\hline & Maria & 12 (37.5\%): length, coherence, quality \\
\hline & Pink & 11 (34.4\%): length, coherence, expressiveness, quality \\
\hline \multirow[t]{3}{*}{ Fear } & Silence & 6 (18.8\%): length, quality \\
\hline & Halloween & 4 (12.5\%): length, coherence \\
\hline & Marathon & 5 (15.6\%): length, coherence, expressiveness, quality \\
\hline \multirow[t]{3}{*}{ Sadness } & Officer 2 & 2 (6.3\%): length, coherence \\
\hline & Killing & 13 (40.6\%): length, coherence, expressiveness, quality \\
\hline & Champ & 9 (28.1\%): length, quality \\
\hline Neutral & Hannah & 12 (37.5\%): length, expressiveness, quality \\
\hline \multirow[t]{3}{*}{ Clips } & Emperor & 18 (56.3\%): length, expressiveness, quality \\
\hline & Crimes & 21 (65.6\%): length, coherence, quality \\
\hline & President & 19 (59.4\%): length, coherence, expressiveness, quality \\
\hline
\end{tabular}


Scientific Research Publishing (SCIRP) is one of the largest Open Access journal publishers. It is currently publishing more than 200 open access, online, peer-reviewed journals covering a wide range of academic disciplines. SCIRP serves the worldwide academic communities and contributes to the progress and application of science with its publication.

Other selected journals from SCIRP are listed as below. Submit your manuscript to us via either submit@scirp.org or Online Submission Portal.
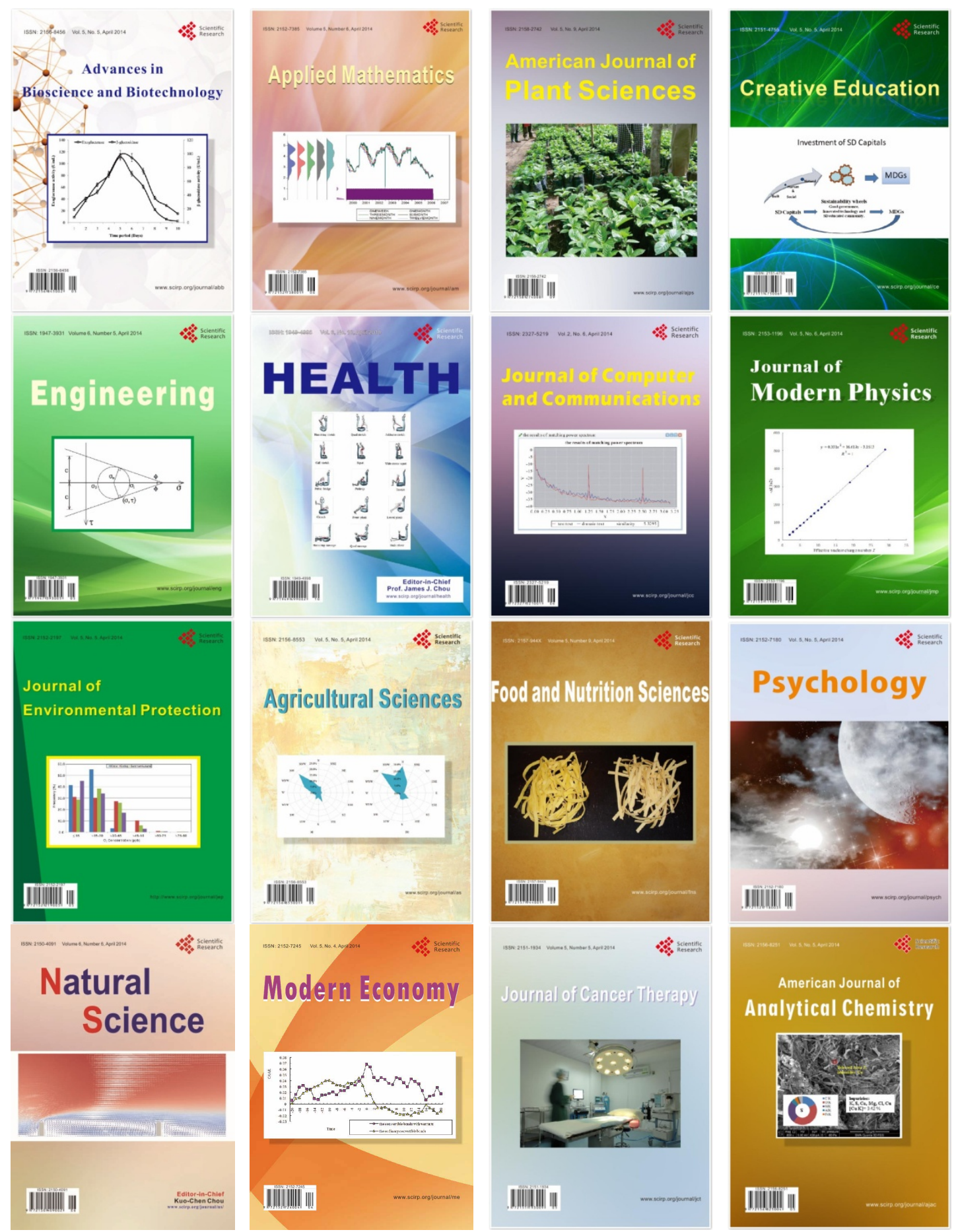